\title{
O Positivismo e a sua influência sobre o Design
}

\author{
Positivism and its influence on Design
}

\author{
Cruz, Tiago André da; Mestrando; \\ Universidade Federal de Santa Catarina - UFSC \\ tiagoitajai@gmail.com \\ Perassi, Richard Luiz; Doutor; \\ Universidade Federal de Santa Catarina - UFSC \\ richard.perassi@uol.com.br \\ Horn, Milton Luiz Vieira; Doutor; \\ Universidade Federal de Santa Catarina - UFSC \\ mlvieira@cce.ufsc.br
}

\begin{abstract}
RESUMO
O design possui fundamentos filosóficos em sua forma de pensar e agir baseados no Positivismo, que foi utilizado como base para sua validação social no surgimento da indústria e como princípio para a formação do método de projeto de design. Esse artigo faz uma revisão bibliográfica das obras positivistas e das publicações da área de design que apresentam a influência desta filosofia no surgimento da profissão, e na evolução do ensino de design.
\end{abstract}

Palavras-chave: design, positivismo, filosofia, metodologia.

\begin{abstract}
Design has philosophical fundamentals in its thinking and acting based on positivism, which was used as the basis for its social validation in the emergence of the industry and as a principle for the formation of the design project method. This article is a literature review of the positivist works and publications in the field of design that presents the influence of this philosophy in the emergence of the profession, and in the development of the design education.
\end{abstract}

Key-words: design, positivism, philosophy, methodology.

\section{Introdução}

O design possui diferentes significados para diferentes autores. Sobre o conceito design, Coelho diz que "o termo possui um caráter polissêmico - a palavra em inglês design, de origem latina de designo" (2008, pg.187). Atualmente, a tendência no uso corrente entre profissionais da área e estudantes é a utilização do termo design indicando o processo de realização de projetos de produtos e peças gráficas, além de virtuais, sendo que é significativa a ampliação de especialidades como design de joias, design de interiores etc. (COELHO, 2006). Assim, ainda que possam divergir os diferentes significados, todos convergem para a atividade de projeto.

A realização do projeto de design é um ato de criação de uma solução. Entretanto, não é resultado exclusivo de uma expressão pessoal ou uma inspiração do designer, mas consequência de um método em que razão é somada à sua própria capacidade inventiva. Como dizem Bayley \& Conran, "hoje, design possui estes dois sentidos: uma mistura útil de expressão criativa e propósito intelectual" 
modo de pensar e agir, e ainda, quais foram as razões que fizeram com que ela fosse utilizada pelo design como arcabouço de valor social, realiza-se assim uma pesquisa sobre o tema principal, a filosofia positivista abordando suas características e sua contextualização na Revolução Industrial, bem como sua inserção nas primeiras escolas de design do mundo e do Brasil.

A natureza da pesquisa é básica, porque visa gerar um maior conhecimento a respeito do das bases filosóficas do design e seus métodos, mas sem o desenvolvimento de uma aplicação prática prevista. O problema é abordado de forma qualitativa e possui o objetivo de descrever através de um pesquisa bibliográfica a influência que a filosofia positivista teve no design (GIL, 1991).

\section{Positivismo}

O Positivismo foi criado por Auguste Comte, nascido em 1798 em Montpellier e jazido em 1857 em Paris. Em 1839 foi publicado o seu "Curso de Filosofia Positiva", em 1851 seu "Sistema de Política Positiva" e logo em seguida, em 1852, seu "Catecismo Positivista". Este filósofo francês "supunha realizar uma missão de regeneração da humanidade" pela sua nova forma de pensar a realidade e buscar a verdade (RIBEIRO, 1996, p. 8). Ele dava tanto crédito à sua filosofia, que acreditava que ela estava "em condições de assegurar integralmente a felicidade da humanidade" (VERDAN, 1998, pg. 126).

O filósofo tinha a proposta de criar uma "uma sistematização real de todos os pensamentos humanos", nas quais se constituía a "primeira necessidade social, igualmente quanto à ordem e progresso" (COMTE, 1996, pg. 71). Assim, Comte fixou quatro objetivos principais para sua filosofia. 0 primeiro seria o de pôr em evidência as leis lógicas do espírito humano. Com base nisso, em segundo lugar, a filosofia positiva poderia promover um reforma geral na educação. Assim, em terceiro lugar, poderia também ser alcançado o objetivo de promover o progresso nas diversas ciências. Por fim, isso levaria, a uma reorganização da sociedade em bases sólidas (DUTRA, 2005).

Desta forma, a filosofia de Comte seria responsável por uma nova e última etapa do pensamento da humanidade. Para ele o desenvolvimento da inteligência em suas diversas esferas, em suas concepções principais e em cada ramo de seus conhecimentos passa sucessivamente por três estados históricos diferentes: estado teológico ou fictício, estado metafísico ou abstrato, estado científico ou positivo (COMTE, 1996, pg.22).

Os três estados seguem uma ordem linear e são reflexo de uma evolução do pensamento humano. O primeiro, o estado teológico, caracteriza-se "pela busca da natureza íntima das coisas, suas causas primeiras e finais. Compreende-se aqui que os fenômenos são produtos da ação direta de agentes sobrenaturais" (DUTRA, 2005, pg.50). O segundo, o estado metafísico ou abstrato, "é um estado intermediário, no qual aquelas entidades das quais nos ocupávamos no estado teológico são substituídos por forças abstratas" (DUTRA, 2005, pg.51). E o terceiro e último, o estado positivo ou científico, caracteriza-se com aquele em que, nós seres humanos, "renunciamos a esse ideal cognitivo, e nos restringimos à descrição de como os fenômenos ocorrem, de modo pelo qual eles se apresentam". O espírito positivo, segundo Comte, "instaura as ciências como investigação do real, do certo e indubitável, do precisamente determinado e útil" (1996, pg.10).

Apesar de desconsiderar qualquer dogma, para Verdan, "Comte é dogmatista principalmente por esta ilimitada confiança na ciência" (1998, pg. 125). Para Ribeiro, esta corrente filosófica "é uma dogmatismo físico e um ceticismo metafísico. É um dogmatismo físico, pois que afirma a objetividade do mundo físico; e é um ceticismo metafísico, porque não quer pronunciar-se acerca da existência da natureza dos objetivos metafísicos" (1996, p. 16). E nas próprias palavras de Comte:

"Vemos, pelo que precede, que o caráter fundamental da filosofia positiva é tomar todos os fenômenos como sujeitos a leis naturais invariáveis, cuja descoberta precisa e cuja redução ao menor número possível constituem o objetivo de todos os nossos esforços, considerando como absolutamente inacessível e vazia de sentido para nós a investigação das chamadas causas, sejam primeiras, sejam finais" (1996, pg.26). 
Assim, tudo aquilo que é teológico ou metafísico, aquilo que não pode ser acessado pela objetividade do raciocínio humano deve ser desconsiderado. Para Comte, de acordo com Ribeiro, o axioma fundamental do positivismo é: "Tudo é relativo, e isso é a única coisa absoluta" (1996, p. 22). Para ele, o método positivo inaugura o pensar "o real frente ao quimérico, o útil frente ao inútil, o certo frente ao incerto, o preciso frente ao vago, o relativo frente ao absoluto, o orgânico frente ao inorgânico, e o simpático frente à intolerância" (RIBEIRO, 1996, p. 17).

Para o pai do Positivismo, "a verdadeira filosofia se propõe a sistematizar, tanto quanto possível, toda a existência humana, individual e, sobretudo coletiva, contemplada ao mesmo tempo nas três ordens de fenômenos que a caracterizam, pensamentos, sentimentos e atos" (COMTE, 1996, pg.75). Assim, a sistematização dos conhecimentos objetivos deve ser aplicada a todas as atividades humanas. $\mathrm{E}$, a partir deste princípio, aqui também estaria incluído o design.

Entretanto, como ciência positiva, o design, atualmente considerado como ciência social aplicada, poderia ocupar a última, mas não menos importante posição. Comte classificou as ciências em ordem crescente de complexidade que "permite estabelecer a sequência: matemáticas, astronomia, física, química, biologia e sociologia" (1996, pg.11). Para ele, as ciências posteriores da escala deveriam estar baseadas em suas anteriores, assim, para compreender a sociologia, deveria primeiro compreender todas as leis promulgadas pelas suas ciências dianteiras. No positivismo cada atividade não só depende de certa ciência correspondente, mas, ao mesmo tempo, de várias, de modo de que estas atividades se manifestam diretamente de quase todas as diversas ciências principais (COMTE, 1996).

E, ainda que Comte não tenha escrito nada específico ao design, pode aqui ser feito um paralelo ao que ele escreveu sobre a engenharia. Em suas palavras:

\footnotetext{
"Entre os cientistas propriamente ditos e os diretos efetivos dos trabalhos produtivos, começa a formar-se, em nossos dias, uma classe intermediária, a dos engenheiros, cuja destinação especial é organizar teoria e prática. Sem ter, de modo algum, em vista o processo dos conhecimentos científicos, ela os considera em seu estado presente para daí deduzir as aplicações industriais de que são suscetíveis. Tal é, ao menos, a tendência natural das coisas, embora ainda exista muita confusão. $O$ corpo de doutrina próprio a essa nova classe, e que deve constituir as teorias verdadeiras e diretas de diferentes artes, poderia sem dúvida, dar lugar a considerações filosóficas de grande interesse e importância real. Mas um trabalho que as abrangesse juntamente com aquelas, fundadas sobre as ciências propriamente ditas, seria hoje totalmente prematuro, pois essas doutrinas intermediárias entre a teoria pura e a prática direta não estão ainda formadas. Delas existem apenas, até agora, alguns elementos imperfeitos relativos às ciências e às artes mais avançadas e que permitem somente conceber a natureza e a possibilidade de semelhantes trabalhos para o conjunto de operações humanas" (COMTE, 1996, pg.49).
}

Assim, esta relação entre atividade científica e atividade industrial poderia também se referir ao design, visto que ambas as atividades humanas, engenharia e design, da forma como hoje atuam na sociedade, tiveram início na Revolução Industrial.

Para Comte, os avanços científicos são resultados de nossa atividade intelectual, que se estimula "suficientemente com a pura esperança e descobrir as leis dos fenômenos, com o simples desejo de confirmar ou infirmar uma teoria" (COMTE, 1996, pg.25). Para o filósofo, a atividade humana que realizaria estas descobertas, deveria se basear no método positivo. Segundo Dutra: "As ciências positivas devem encontrar as leis que expressam as relações corretas entre os fenômenos, isto é, devem descobrir como tais fenômenos são dados nas observações" (2005, pg.52). Assim, somente através do método da observação dos fenômenos poderia se descobrir a realidade.

E em suas próprias palavras: "A única unidade indispensável (ao positivismo) é a unidade do método, que pode e deve evidentemente existir e já se encontra, na maior parte, estabelecida" (COMTE, 1996, pg. 42). Para Dutra "os positivistas são aliados das ciências empíricas e defensores de seus procedimentos, que são baseados sobretudo na observação e na experimentação" (2005, pg. 47). 
Assim, já pode ser observado o início da influência do positivismo no design, que, apesar de ciência social, utiliza dos mesmo s métodos de observação e experimentação no avanço de seus próprios conhecimentos.

Para o pensamento positivo, independentemente do caráter da atividade humana, "uma idêntica metologia produz convergência e homegeindade de teorias" (COMTE, 1996, pg. 10). E assim, "apenas o império da positividade dos dados observacionais poderia nos auxiliar na difícil tarefa de separa o certo do errado" (DUTRA, 2005, pg. 48). O que torna hoje, mais brando para o design, a utilização do método positivo em partes de seu processo para que seus resultados sejam considerados mais científicos e acertados.

O design assim, de certa forma, também se encontra sujeito ao pensamento positivo, da objetividade e das relações entre os fenômenos naturais, encontrados comumente na ciência.

Além de influenciar o design, a filosofia e a sua importância dada ao método positivo de Comte, foi o contexto histórico no qual o surgimento de um nova atividade, o projeto de produtos industriais, estava inserido.

\title{
Revolução Industrial e Positivismo
}

Até o século XVIII todos os produtos eram frutos do trabalho de uma só pessoa, o artífice, que o conceituava e o produzia, sendo responsável por todo o processo da realização de uma ideia em um produto físico. Antes da Revolução Industrial "a habilidade do artesão e seu conhecimento sobre PROCESSOS e MATERIAIS eram a garantia da QUALIDADE técnica dos artefatos" (COELHO, 2008, pg. 109).

Uma interpretação da Revolução Industrial é apresentada por Bayley \& Conran, que mostram que:

\begin{abstract}
“ocorreu quando certos processos tecnológicos foram percebidos e utilizados por engenheiros e empresários na Grã-Bretanha. Embora estes mesmos processos tecnológicos fossem conhecidos por homens de ciência em toda a Europa, os britânicos desfrutaram de um cenário de estabilidade política, um governo centralizado, uma tradição de livre iniciativa e da filosofia utilitária, e também de uma abundância de recursos naturais, que juntos permitiram a estes engenheiros e empresários a tomar a primeira vantagem comercial da indústria." (2007, pg. 15)
\end{abstract}

O resultado desta revolução foi a separação da conceituação e da produção de produtos, criando ofícios distintos. Como afirma Forty: "Na história de todas as indústrias, o design tornase necessário como uma atividade separada da produção assim que um único artífice deixa de ser responsável por todos os estágios da manufatura, da concepção à venda" (2007, pg. 43).

Assim, "o design dentro de seu contexto histórico, seria o produto do empreendimento coletivo típico da SOCIEDADE industrial" (COELHO, 2006, pg. 18). Forty apresenta amplia este contexto ao considerar, além dos fatores sociais e tecnológicos, também os econômicos, para ele: "O que é descrito como progresso nas sociedades modernas é, na verdade, sinônimo, em larga amplitude, de uma série de medidas provocadas pelo capital industrial" (FORTY, 2007, pg. 19).

Esta criação de "uma nova classe de ser: o designer" (BAYLEY \& CONRAN, 2007, pg. 17) foi resultado de um "novo paradigma industrial, sob diversos aspectos: a INOVAÇÃO, com a posta em prática de diversos novos inventos, a nova mentalidade científica que é incorporada à atividade industrial, assim como os novos modos de produção" (LEITE, 2008, pg. 99).

Assim, pode-se perceber que a criação da atividade do design foi consequência de uma mudança nos processos de fabricação, mas a sua validação perante a sociedade foi resultado de uma nova forma de pensar.

O Positivismo "que se pretendeu inovador, impregnou todo o ambiente cultural do século XIX, universalizando a experiência e resolvendo nela toda a realidade" (RIBEIRO, 1996, p. 55). A Revolução Industrial, assim também se viu sob a filosofia positivista. Nesta época, os industriais utilizaram esta filosofia para legitimar seus objetivos, de crescimento empresarial e aumento de poder social, com os 
ideais de ordem e progresso em busca de uma sociedade melhor.

Somado ao contexto século XVIII, em que:

"havia uma crença dominante no poder da razão. Ele (o positivismo) andava de mãos dadas com o desejo de investigar a natureza, tanto do mundo natural e o homem. A Literatura estava viva com metáforas da indústria, as primeiras fábricas de poetas oferecendo visões espetaculares do mundo futuro" (BAYLEY \& CONRAN, 2007, pg. 15).

Assim a filosofia de Comte e a esperança na indústria formaram a constituição filosófica do pensamento do design frente à sua participação na sociedade.

Para os industriais burgueses, o positivismo vinha expor de maneira sistemática a sua confiança em seu próprio impulso transformador de estruturas. Na Europa, berço da revolução industrial, a filosofia positivista servia para justificar as novas atitudes da burguesia em sua fé no progresso retilíneo da humanidade (RIBEIRO, 1996).

Niemeyer mostra que "esse método de conhecimento da realidade carrega uma positividade que, na política, o faz adequado às aspirações ideológicas de um projeto de sociedade progressista, independente de sua orientação e, na ciência, o faz constituir-se em estrutura explicativa dos fenômenos" (2007, pg. 58).

A lógica para tal crédito dado pela na indústria foi baseada na fórmula máxima do positivismo: “O Amor por princípios, e a Ordem por base; e o Progresso por fim" (RIBEIRO, 1996, p. 28). Para o próprio Comte "a mentalidade tecnológica desempenharia também relevante pepel de coesão social, fundamentando a vida moral" (1996, pg. 9). Na dialética positivista, o amor busca a ordem e a impele para o progresso; e a ordem consolida o amor e dirige o progresso; e o progresso desenvolve a ordem e reconduz o amor (RIBEIRO, 1996).

Entretanto, hoje é sabido que se deve limitar a esperança de uma transformação social baseada no progresso. Como mostra Forty:

\footnotetext{
"Apesar de todos os seus benefícios, o progresso pode ser uma experiência dolorosa e perturbadora. Nossa reações a ele são frequentemente ambivalentes: queremos as melhorias e os confortos que ele proporciona, mas, quando ele nos impõe a perda de coisas que valorizamos, compele-nos a mudar nossos pressupostos básicos e nos obriga a ajustar-nos ao novo e desconhecido, nossa tendência é resistir" (2007, pg.19).
}

E ainda, o próprio Comte já afirmava, diferentemente da apropriação da ciência pelos industriais que assim validavam sua expectativa em uma transformação social pela indústria, que:

\footnotetext{
"Seja quais forem os imensos serviços prestados à indústria pelas teorias científicas [...], não devemos esquecer que as ciências possuem, antes de tudo, destinação mais direta e mais elevada, a saber, a de satisfazer à necessidade fundamental, sentida por nossa inteligência, de conhecer as leis dos fenômenos" (1996, pg.48).
}

Dentro deste ambiente, o positivismo "passa então [...] a dominar o pensamento típico do século XIX, com método e como doutrina. Como método, embasado na certeza rigorosa dos fatos de experiência como fundamento da construção teórica; como doutrina, apresentado-se como revelação da própria ciência" (RIBEIRO, 1996, p. 13).

E além de ser apropriado pela indústria, a filosofia Comtiana passa também a ser base para a formação em design, já que esse profissional seria orientado pelos valores de ordem e progresso utilizados pelos industriais.

\section{A influência do Positivismo nas escolas de design}


Pode-se verificar que o ensino de design sofreu influência do Positivismo no entusiasmo com que as primeiras, e mais influentes, escolas da história do design, a Bauhaus e a Escola de Ulm, abraçaram a filosofia de Comte.

A Bauhaus "cuja influência no mundo da arte e design pode ser comparada com a influência da teoria da relatividade na física" (BAYLEY, CONRAN, 2007, pg. 162) foi fundamental para o design como hoje se conhece.

Esta escola, que existiu na Alemanha de 1919 a 1933, buscava a união da arte e da técnica, o aprendizado pela prática, e possuía por base os estudos teóricos e a experimentação como meio de descoberta (NOGUEIRA, 2006, pg. 111). Sua "principal contribuição para o design foi a sua teoria da educação. Como floresceu nos anos vinte, seu o programa pedagógico foi muitaz vezes expresso em metáforas que se baseou em carros e aviões, e assim a Bauhaus passou a representar a cultura da máquina na arte" (BAYLEY \& CONRAN, 2007, pg.87).

Antes da Bauhaus, o ensino da arte tinha sido pouco mais do que atividades de desenho, pintura e escultura organizadas e Walter Gropius, o criador da escola, fez a educação em artes um processo sistemático (BAYLEY \& CONRAN, 2007). A racionalidade e positividade, e o otimismo da indústria como transformador social, deste arquiteto e professor foi responsável pela filosofia da escola, que consequentemente, também influenciou todas as outras escolas de design posteriores (ARGAN, 2005).

A Bauhaus possuia a rígida racionalidade de seu criador, e tinha o objetivo de criar as condições para uma arte sem inspiração, que criasse construtivamente e formasse a nova realidade. Na escola, o mito da inspiração ou da espontaneidade a partir de fontes metafísicas era visto como presunção e que apenas o projeto baseado na objetividade da razão poderia representar o ideal industrial para a configuração de uma nova sociedade (ARGAN, 2005). Assim, de forma positivista, "Não há dúvida de que Gropius atuou no âmbito de uma cultura burguesa" (ARGAN, 2005, pg. 9) e a que "Bauhaus defendeu a busca da 'verdade'"(BAYLEY \& CONRAN, 2007, pg. 162).

Outra escola importante, foi a Hochschule für Gestaltung Ulm, ou Escola de Ulm, fundada também na Alemanha em 1952. Acreditava que "a ênfase em novas formas era irrelevante, ao invés disso, era necessário formular princípios e novas metodologias que permitissem aos designers lidar de modo flexível com as complexas exigências da tecnologia e da indústria" (NOGUEIRA, 2006, pg. 111).

A preocupação com o método objetivo do design na escola era visível, ao citar Gunther Schmitz, aluno e professor da Escola de ULM: "A tendência para a objetivação das atividades criativas se alimentava do perigoso anseio de produzir uma METODOLOGIA que pudesse automaticamente conduzir a resultados originais e perfeitos" (REDIG, 2008, pg. 175).

Tomas Maldonado, o segundo diretor da escola, com sua "presença cerebral dominou o pensamento na Hochschule: o seu interesse estava na sistematização do design, tanto em termos do processo de fazer, quanto em termos do processo de análise, ou de 'leitura' de objetos de design" (BAYLEY \& CONRAN, 2007, pg. 208). O propósito da escola era tornar o processo de design um processo sistemático (BAYLEY, CONRAN, 2007).

E mesmo que de existência breve, ambas as escolas que fundamentaram a formação em design, exportaram sua filosofia para outras escolas no mundo e também no Brasil. A filosofia de Comte, como mostra o filósofo brasileiro José Arthur Giannotti, no prefácio do livro de Comte, "solo mais fértil foi encontrado pelo positivismo comtiano [...] em países de menor tradição cultural e carentes de ideologia para seus anseios de desenvolvimento. Esse fenômeno ocorreu na América do Sul sobretudo no Brasil" (COMTE, 1996, pg.13)

Segundo Ribeiro, a primeira manifestação do positivismo no Brasil ocorreu em 1844 e desde então demonstrou uma grande influência (1996, pg. 66), chegando a estampar a bandeira do país. 0 autor corrobora: "A nossa bandeira, com seu Ordem e Progresso, mostra o quanto a doutrina positivista teve aceitação mesmo entre os nossos republicanos históricos" (RIBEIRO, 1996, pg. 67)

Especificamente em relação ao design, "do ponto de vista histórico, a adoção de métodos científicos na área do design remonta aproximadamente à década de 50 , quando o design rompeu alguns vínculos importantes que mantinha ainda com a tradição artística na produção de artefatos" (CIPINIUK \& PORTINARI, 2006, pg. 29). Na mesma época, o Brasil passava por um período de transição no qual havia que se criar as condições sociais para que a indústria firmasse posição como 
um importante setor da economia, permitindo a modernização capitalista do país (NIEMEYER, 2007).

Entretanto, ainda que os industriais brasileiros não conheciam o que fazia o profissional de design, "era necessário suprir a demanda de projetos de produtos e de comunicação visual que adviriam da atividade econômica crescente e da indústria nacional nascente" (NIEMEYER, 2007, pg, 64). E para a formação deste novo profissional, era preciso "colaborar com toda nossa tradição positivista com sua crença na ciência como paradigma de uma ordem racional geradora de progresso. Não podemos perder de vista que essas estratégias organizacionais faziam parte de um momento histórico" (NIEMEYER, 2007, pg, 64).

Uma influência direta do Positivismo na formação do design brasileiro é apresentada por Cipiniuk \& Portinari, ao afirmar que a Escola de Ulm inspirou o modelo de ensino do design no Brasil, com a fundação da ESDI - Escola Superior de Desenho Industrial, primeira escola de ensino superior no país, em 1962 (2006). Assim, a escola alemã, que baseava sua filosofia no pensamento de Comte, consequentemente influenciou o ensino do design no Brasil; que seguiu a tradição da filosofia positivista.

Segundo Niemeyer, a formação em design estruturava-se segundo dois eixos fundamentais: o de uma utopia social e o de um vocabulário plástico, responsáveis por um projeto de design resultado de uma síntese da ordem racional (2007). E como valor social do design, autora ainda mostra que:

\footnotetext{
"envolvem uma concepção de progresso como movimento em direção a um futuro melhor, como processo ativo que gera transformações e renovações. A validade epistemológica deste conceito de progresso estava relacionada com a positividade do método de investigação das ciências que se propõe uma tarefa crítica, interrogativa do mérito do passado e, ao mesmo tempo, uma tarefa construtiva de um conhecimento verdadeiro e universal" (NIEMEYER,2007, pg. 58).
}

Desta forma se iniciou a formação em design no mundo e no Brasil, com a aplicação do método positivista em projetos e com a crença na indústria como transformador social. $E$, sabendo que para compreender o momento atual é necessário estudar o passado, a verificação da influência do Positivismo nas raízes do design, pode ainda ser verificado em seus métodos, muitos dos quais são utilizados até hoje.

\section{As influências positivistas na metodologia de design}

O Positivismo apresentava uma forma de pensar as relações sociais, das quais a indústria, como fonte de ordem e progresso, e a razão, como método sistemático de se descrever a realidade foram fundamentais para a validação do método de design.

Como consequência de novas formas de produção e pensamento, o design surge. Para explicar seu trabalho, Löbach diz que "o designer industrial pode ser considerado como produtor de ideias, recolhendo informações e utilizando-as na solução de problemas que lhe são apresentados" (2001, pg. 139). E o que diferencia o designer de outros profissionais que também solucionam problemas é o seu método.

Os autores Cipiniuk \& Portinari classificam os métodos científicos em três grandes grupos: o primeiro é o das ciências da natureza como a física e a biologia, pesquisas experimentais e indutivas, que estudam os elementos e os fenômenos naturais, o segundo é o das ciências formais como a matemática e da lógica, com demonstrações, e que possui o genérico como objeto de estudo; e o terceiro e último grupo é das ciências humanas como a psicologia e a sociologia, que estudam situações muito complexas e diversas, e possui como método de validação de seus argumentos o assentimento e o consenso. E este último grande grupo é considerado pelos autores como as ciências "menos precisas", mostrando aqui, em suas próprias aspas, certa dose de positivismo pessoal ou ironia (2006, pg. 28).

Entretanto, ainda que o método de design seja próprio, ele se baseia em métodos científicos para que seus resultados sejam aceitos como verdadeiros. Como afirmam Cipiniuk \& Portinari, "Em princípio não deveria haver diferenças notáveis entre métodos de pesquisa científica e métodos de 
desenvolvimento de projeto, salvo o maior rigor e densidade desses instrumentos no primeiro caso" (pg.27, 2006). Desta forma, a facilidade em utilizar o pensamento científico que designers encontram para legitimar seus resultados, possui raízes no positivismo, sendo que nele a objetividade dos fatos é a única forma de se encontrar a verdade.

E outra forma de validação do design como formação e profissão, frente a outros profissionais que não utilizam o seu método é utilizado. Niemeyer apresenta que:

A fala corporativa é sempre aquela que lida com a realidade por meio de um aparato "científico" que validaria sua infalibilidade. Daquele modo, à concorrência dos "práticos" no ramo de projetos poderia se opor um discurso do design como atividade pluridisciplinar, cuja responsabilidade cabia ao profissional que dominaria seu campo de abrangência. Reforçando o apreço àquela concepção do trabalho do designer, tínhamos a colaborar toda nossa tradição positivista com sua crença na ciência como paradigma de uma ordem racional geradora de progresso. 0 designer teria condições de apontar as deficiências do presente e propor as medidas convenientes de sua superação, com base em investigações que the dariam um arsenal "teórico-científico" de improvável contestação. A sua fala seria, então, por meio das pesquisas empíricas, aquela de quem conhece a realidade pelas lentes da ciência e, por isso, tida como a única digna de confiança (2007, pg. 106).

Assim, seu método e a própria validade de seu método é que torna o design aquilo que ele é. Para Cipiniuk \& Portinari, "se em um primeiro momento o sujeito cria o método, uma ótica e uma maneira determinada de pensar e agir, no momento seguinte, a persistência dessa ótica e dessa maneira de agir modela a realidade e, por extensão, o próprio sujeito (2006, pg. 33). Uma consequência direta do positivismo no pensamento das escolas de formação em design pode ser verificada em seu método, isto é, sua forma de pensar e agir. Como visto na história das primeiras escolas de design, o método foi forjado de modo positivista. Como mostram Cipiniuk \& Portinari:

"A intuição e a criatividade foram substituídas por métodos, a habilidade por instrumentos tecnológicos e, mesmo aquilo que não pode ser quantificado, mas qualificado, como o valor estético, tornou-se matéria submetida ao cálculo matemático, por exemplo como na Estética Numérica de Max Bense. Esse período, que se caracterizou pela tentativa de sistematizar ao extremo as tarefas implícitas à atividade do designer, ficou conhecido como a a era da "metodolatria", pois se acreditava que seria possível explicitar, quantificar e avaliar matematicamente toda operação de um projeto" (2006, pg. 31).

Nogueira apresenta ainda, a influência que o empirismo adotado pelo Positivismo teve na evolução do método de design, para o autor:

"Com o DESENVOLVIMENTO do empirismo e da aproximação crescente entre o conhecimento científico e a produção MATERIAL, as técnicas foram particularizadas e classificadas em grupos cada vez mais específicos, até o surgimento da expressão "técnicas racionais" (cognitivas, estéticas, morais, políticas, econômicas, produtivas etc.); e, modernamente, a compreensão do termo está ainda mais diretamente associada às técnicas produtivas, ou seja, àquelas que dizem respeito ao comportamento do homem em relação à produção de bens" (2008, pg.110).

Entretanto, a obsessão pela metodologia deve receber cautela. Segundo Nojima: "As metodologias não são nem podem ser receituários ou instrumentos que se oferecem para serem aplicados a qualquer campo, todos os assuntos, a todos os problemas de pesquisa ou a qualquer projeto" (2006, pg. 123).

Ao considerar os métodos de projeto utilizados pelo design, é uma tarefa árdua imaginar a complexidade de aplicar métodos sistemáticos, já que concorrem procedimentos e técnicas derivados daquelas áreas científicas, pois se considera que o design, como ciência social aplicada, é uma atividade 
interdisciplinar, que emprega no desenvolvimento de um projeto conhecimentos oriundos de várias fontes de saber. Por isso, o emprego da objetividade científica, defendida pelo positivismo, pretende ser capaz de "emprestar ao design, ao menos em sua aparência operacional, caráter científico" (CIPINIUK \& PORTINARI, pg.30, 2006).

Como resultado do pensamento positivista no papel social do design atualmente, Coelho, apresenta o conceito de desenvolvimento do ponto de vista do design, que possui bases comtianas. Segundo o autor, "esse CONCEITO de desenvolvimento é abrangente, configurando um sistema em cujo centro ele se posiciona:

(I) O design busca, no curto prazo, o desenvolvimento MATERIAL e tecnológico;

(II) que no médio prazo leva ao desenvolvimento econômico; e

(III) que, por sua vez, leva no longo prazo ao desenvolvimento sociocultural e político"

(2008, pg. 184).

Assim, o design continua, até hoje, a tradição positivista ao acreditar que o desenvolvimento ocorre pelo incremento de produtos industriais, que levam a uma ordem econômica e por último a um progresso social. Como mostra Forty: "O sucesso do design no uso imaginário tecnológico para transmitir a visão de um futuro livre de desconforto e ansiedades foi um dos fenômenos mais peculiares do século XX" (FORTY, 2007, pg.274).

\section{Conclusão}

Por meio da presente revisão bibliográfica, o design pode compreender melhor a sua forma de pensar e agir, baseadas na filosofia comtiana, que, de início, foi utilizada como base para a validação social do crescimento industrial rumo a uma ordem a um progresso, como fundamento para a formação do profissional designer e como método de projeto de design.

Se hoje o design utiliza de experimentação e observação para tomar decisões em seus projetos e tira conclusões baseadas em dados científicos, pode-se aqui verificar a influência de Auguste Comte em seu método.

E ainda, se o design, como elemento da dinâmica social, acredita poder transformar a sociedade com o desenvolvimento de novos produtos industriais, para assim, baseado no progresso, buscar a ordem, a base da filosofia positivista também possui sua parcela de influência.

Considera-se que a apresentação de um levantamento deste tipo, ainda que breve, possa aumentar o embasamento sobre de onde veio e onde está a argumentação de pensar e agir do design. E ainda, que este entendimento possa oferecer recursos para novas reflexões do que o design, como labor e como ciência, possui como papel social, principalmente em uma época de produção pósindustrial e de filosofia pós-moderna.

Para concluir, vale citar a questão de Nogueira: "Operamos hoje com muitos dos moldes de realidades passadas e parece que não estamos dando conta da demanda da realidade do presente. 0 que é o design hoje? Ou o que ele poderia ser? Ou o que ele poderá vir a tornar-se?" (2006, pg. 111).

Observa-se, portanto, que se mostra de grande valia uma aproximação mais efetiva entre design e a filosofia, tendo em vista que para se compreender o design, é importante entender os princípios filosóficos que colaboram para determinar o que ele mesmo é. E para que se possa determinar o que o design pode vir a ser, no presente e no futuro, o reconhecimento de sua história e sua filosofia se faz imprescindível.

\section{Bibliografia}

ARGAN, Giulio Carlo. Walter Gropius e a Bauhaus, Rio de Janeiro: José Olympio, 2005.

BAYLEY, Stephen, CONRAN, Terence. Design - Inteligence made visible. Buffalo, New York: Firefly Book, 2007 
BÜRDEK, Bernhard; Diseño - História, teoría y práctica del diseño industrial - Barcelona: Editorial Gustavo Gili, SA - 2. edición 1999.

CIPINIUK, Alberto; PORTINARI, Denise B. Sobre métodos de Design. In: COELHO, Luiz Antonio L. (Org.) Design Método. Rio de Janeiro: Ed. PUCRio; Teresópolis: Novas Idéias, 2006. p. 17-38.

COELHO, Luiz Antonio L. (organizador). Conceitos-chave em design. Rio de Janeiro: Ed. PUC-Rio. Novas Idéias, 2008

COELHO, Luiz Antonio L. (organizador). Design Método. Rio de Janeiro: Ed. PUC-Rio; Teresópolis: Novas Idéias, 2006

COMTE, Auguste. Os pensadores. São Paulo: Círculo do Livro, 1996.

DUTRA, Luiz Henrique de Araújo. Oposições Filosóficas - A epistemologia e suas polêmicas. Florianópolis; Editora da UFSC, 2005

FORTY, A. Objetos do desejo: design e sociedade desde 1750. 1a ed., São Paulo, Cosac Naify, 2007.

GIL, Antonio Carlos. Métodos e técnicas de pesquisa social. São Paulo: Atlas, 1999.

LEITE, João de Souza. Tudo pelo social: O debate sobre mercado e sociedade na educação de design. In: COELHO, Luiz Antonio L. (Org.) Design Método. Rio de Janeiro: Ed. PUCRio; Teresópolis: Novas Idéias, 2006. p. $99-108$.

LÖBACH, Bernd. Design Industrial: Bases para a configuração dos produtos industriais. Tradução Freddy Van Camp. São Paulo: Editora Blucher, 2001.

NEUMANN, William Lawrence. 2003. Social Research Methods: Qualitative and Quantitative Approaches. 5th ed. Boston: Allyn and Bacon.

NIEMEYER, Lucy. Design no Brasil: Origens e instalação. Rio de Janeiro: 2AB, 2007

NOGUEIRA, Cristine. Design: Tempo e Lugar. In: COELHO, Luiz Antonio L. (Org.) Design Método. Rio de Janeiro: Ed. PUCRio; Teresópolis: Novas Idéias, 2006. p. 109 -122.

NOJIMA, Vera Lúcia. Os Estudos das Linguagens como Apoio aos Processos Metodológicos do Design. In: COELHO, Luiz Antonio L. (Org.) Design Método. Rio de Janeiro: Ed. PUCRio; Teresópolis: Novas Idéias, 2006. p. $123-134$.

PORTINARI, Denise B. Por uma Cultura do Método: algumas reflexões sobre o ensino da disciplina de "Questões Metodológicas". In: COELHO, Luiz Antonio L. (Org.) Design Método. Rio de Janeiro: Ed. PUCRio; Teresópolis: Novas Idéias, 2006. p. 162-168.

REDIG, Joaquim. Design e Metodologia: procedimentos próprios do dia-a-dia do designer. In: COELHO, Luiz Antonio L. (Org.) Design Método. Rio de Janeiro: Ed. PUCRio; Teresópolis: Novas Idéias, 2006. p. 169-177.

RIBEIRO, João. O que é Positivismo. São Paulo: Editora Brasiliense, 2a. Reimpressão, 1996

VERDAN, André. O Ceticismo Filosófico. Florianópolis: Ed. Da UFSC, 1998 